\title{
Design of micro solar power generation system
}

\author{
Qing Wang ${ }^{1, *}$, Tian Ying $\mathrm{Li}^{1}$,Ying Chen ${ }^{1}$, Xin Xiu Xie ${ }^{1}$ and Ao Pan $^{1}$ \\ ${ }^{1}$ School of electrical \& energy engineering, Nantong Institute of Technology, China
}

\begin{abstract}
In this paper, the authors put forward a design of solar power generation system, mainly due to the authors in the daily learning process often need stability of $5 \mathrm{v}$ DC regulated power supply. The system mainly include solar panels, solar charge controller (i.e., can realize the overcharge, discharge, overvoltage, undervoltage control functions), lithium batteries, DC - DC booster module and load equipment.The authors determine the hardware circuit selection through reasonable analysis and calculation.Finally, the stability and reliability of the designed micro solar power generation system were verified by experiments, which meet the expected goals and requirements of the authors.
\end{abstract}

\section{Introduction}

Because the total amount of traditional energy is limited and the development and utilization will pollute the environment, many countries have strengthened their support for the development of new energy. China's per capita energy consumption is only half of the world's per capita energy consumption. It can be seen that China's energy problem is also in urgent need of solution. If it is not solved as soon as possible, energy problem will have an impact on the economic development of our country. Our country's solar power generation market is developing slowly. Also hotovoltaic industry accounts for a very low proportion in the global market, and it's development obviously lags behind that of western countries. However, China has also formulated the corresponding development plan to promote the development of photovoltaic industry. In recent years, the development of photovoltaic power generation in China is relatively rapid, showing a development trend year by year.It is expected that the installed capacity of photovoltaic in China will reach $1000 \mathrm{GW}$ by 2050.With the continuous reduction of power generation costs and the gradual improvement of power quality, the development of this industry has become more favorable.In China, centralized photovoltaic power generation accounts for a large proportion, but with the support of national policies, the proportion of distributed photovoltaic power generation will gradually increase, distributed photovoltaic power generation will become a new development trend.

Foreign countries have made corresponding development plans for photovoltaic power generation, thus promoting the development of photovoltaic industry in China. Germany advocates the self-use of photovoltaic power generation systems below $500 \mathrm{KW}$, larger than $500 \mathrm{KW}$ less than $2 \mathrm{MK}$ "feed-in price", larger than $2 \mathrm{MK}$, there is no subsidy.Japan, on the other hand, has adopted a subsidy policy, which is very high, reaching 42 yen per kilowatt hour. The United States has taken a lot of measures for the development of photovoltaic industry, and the budget is also growing year by year. Overall, American support for solar power generation is mainly in the investment environment. The global photovoltaic market is divided into three categories. The first is Europe, because of its early development, its installed capacity has always accounted for a lot of proportion in the global total installed capacity. The second category is China and the United States, they are the emerging countries that just entered the photovoltaic development a few years ago. The third category is India and other countries, they only began to attach importance to the development of photovoltaic power generation in recent years, there is still a lot of room for development. According to the latest data, the $\mathrm{PV}$ power generation market is shifting to emerging markets.

\section{Design of Solar Power supply system}

\subsection{Selection of solar panel}

Solar panels are widely used as semiconductors, and now there are many kinds of solar panels. Solar cells can be divided into silicon solar cells, compound semiconductor solar cells and organic semiconductor solar cells according to different materials. Among them, silicon solar cells are widely used, silicon solar cells can be divided into single crystal, polycrystal and amorphous silicon, the conversion efficiency of single crystal silicon is the highest, up to $24 \%$, but the cost is high; the conversion efficiency of polysilicon is about $16 \%$, and its cost is relatively low; the conversion efficiency of amorphous silicon solar cells is low, the performance is not stable enough, and there is still great room for development. The comparison of solar silicon materials is shown in Table 1.

\footnotetext{
* Corresponding author: wangq@ntit.edu.cn
} 
Table 1. Solar silicon material comparison table

\begin{tabular}{|c|c|c|c|}
\hline & $\begin{array}{c}\text { transfer } \\
\text { efficiency }\end{array}$ & prime cost & stability \\
\hline $\begin{array}{c}\text { monocrystalline } \\
\text { silicon }\end{array}$ & About $18 \%$ & Higher & High \\
\hline $\begin{array}{c}\text { polycrystalline } \\
\text { silicon }\end{array}$ & About $16 \%$ & lower & Medium \\
\hline amorphous silicon & About $10 \%$ & Very low & Low \\
\hline
\end{tabular}

Single silicon and polysilicon are still the most widely used materials, although the conversion efficiency of single silicon solar panels is high, but its cost is also relatively high, if the use of monosylsilicon solar panels is not conducive to control costs, and polysilicon solar panels have been able to meet the needs of the design, so here the choice of cheaper and conversion efficiency is not much less polysilicon solar panels.

The energy conversion efficiency (1) of the solar cell is:

$$
\eta=\frac{V_{o c} I_{s c} F F}{P_{i n}}
$$

In the formula, $\mathrm{V}_{\text {oc }}$ represents open circuit voltage, Isc indicates short circuit current, FF indicates filling factor, and Pin indicates energy intake.

The three basic equations of solar cell work are: current equation

$$
\begin{gathered}
J_{n}=q\left(\mu_{n} n E+D_{n} d n / d x\right) \\
J_{p}=q\left(\mu_{p} p E-D_{p} d p / d x\right)
\end{gathered}
$$

Poisson equation

$$
d E / d x=q\left[p-n+N_{D}^{+}-N_{A}^{-}\right] /\left(\varepsilon \varepsilon_{0}\right)
$$

Continuous equation

$$
\begin{gathered}
d J_{n}(x) / d x=q[R(x)-G(x)] \\
d J_{p}(x) / d x=q[G(x)-R(x)]
\end{gathered}
$$

In the formula $(6), \mathrm{x}$ is the depth of the concentrated incident surface, Jn,Jp is the electron and hole current density.n, $\mathrm{p}$ is the concentration of electrons and holes; $\mu_{n}, \mu_{p}$ is electron and hole mobility; Dn、Dpis the diffusion constant of electrons and holes; $\mathrm{E}$ is the distribution of electric field; $N_{D}^{+}, N_{A}^{-}$is the donor and acceptor concentration after ionization; $\mathcal{E}, \mathcal{E}_{0}$ is a dielectric constant and a vacuum dielectric constant.

At first, it was considered that the device needed $5 \mathrm{~V}$ power supply, so a polysilicon solar panel with low output voltage was selected. It was found that the single chip microcomputer did not work, considering that it may be due to the low power of the solar panel, so it is necessary to re-select a larger polysilicon solar panel, but it cannot be too large and too big to carry, so the solar panel selected after comprehensive consideration is as shown in figure 1. The specific parameters are as follows. The working voltage is $9 \mathrm{~V}$; the working current is 170 $220 \mathrm{~mA}$; the power is 52 ; the size is $115 * 115 * 2 \mathrm{~mm}$.

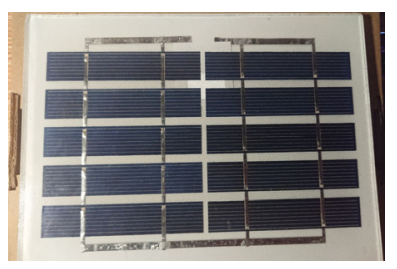

Fig. 1. physical diagram of solar panels

\subsection{Type selection of solar control module}

Solar controller plays an important role in solar power generation system. It has the functions of preventing overcharge overdischarge and electronic short circuit, reverse connection protection of solar cells and batteries, overload protection and so on. Take charge and discharge control as an example, because the battery is easy to cause overcharge and overdischarge, lithium battery is easy to cause damage and reduce life. If the charge and discharge of lithium battery is not controlled, there will be many problems, and the operating cost of the system will be increased, so the controller is particularly important. In addition to accomplishing the established control tasks, the solar controller should also have high reliability, the loss of autogenic power should be as low as possible, and the operation and maintenance should be as simple as possible.

When choosing solar controller, first, we should try our best to choose the one with low power consumption, because the controller has a long working time, if the power consumption is higher, it will waste a lot of electric energy; second, we should choose the one with high charging efficiency; third, we should choose the product with high control accuracy, because the products with low control accuracy often have the problems of design, material selection and so on.

In the selection of solar controller, considering that the final physical volume of the design is small, convenient to carry, and the cost is not high, so the controller is not selected, but a control module that can be used with the previously selected solar panel is selected. The control module is small in volume and the price is also cheap. The physical map is shown in figure 2.

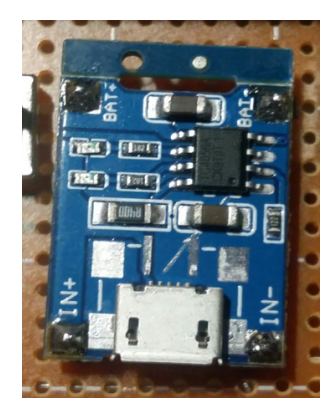

Fig. 2. Real object diagram of solar controller

After the solar panel, controller and lithium battery in the system are connected, pay attention to the positive and negative polarity when connecting the device. if the indicator light is reversed, there is no indication. In particular, when the device is connected, it may cause the device to burn out if it is reversed. 


\section{3 selection of lithium batteries}

In the case of a gap power supply such as solar power generation, it cannot meet the load demand at any time, and thus the energy storage becomes a process that the power generation system has to experience. Energy storage can improve the availability of load, play an important role in the stability of the system and the control of power quality. Energy storage refers to the process of converting one kind of energy into another and then storing it, and the next time it needs to be used, it releases energy. Energy storage technology is divided into physical energy storage, chemical energy storage and other energy storage.

The lithium battery is used to store electric energy, which can be charged again after the power is used in the battery, thereby restoring to the initial state. The lithium battery is mainly used for semi-floating charge in the solar power supply system, that is, the solar energy is charged during the day, and the discharge is carried out at night when there is no solar energy at night.

Compared with the lead-acid storage battery, the lithium battery has the advantages of multiple use times, small weight and volume, long shelf life, and the most important is that the recovery of the lead-acid storage battery can lead to environmental pollution, which is inconsistent with the environmental protection idea of the design, so the lead-acid storage battery is abandoned, And the lithium battery is relatively environmentfriendly and is an ideal choice for the design.

Lithium iron phosphate is mostly used in the positive electrode of lithium battery, and the positive electrode reaction is as follows:

$$
\mathrm{LiFePO} 4 \rightarrow \mathrm{Li} 1 \times \mathrm{xFePO} 4+\mathrm{xLi}^{+}+\mathrm{xe}^{-} \quad \text { (8) }
$$

The positive electrode reaction during discharge is:

$$
\mathrm{Li} 1 \mathrm{xFePO} 4+\mathrm{xLi}^{+}+\mathrm{xe}^{-} \rightarrow \mathrm{LiFePO} 4
$$

The negative pole of the lithium battery adopts graphite, and the negative reaction of the negative electrode during charging is as follows:

$$
\mathrm{xLi}+\mathrm{xe}+6 \mathrm{C} \rightarrow \mathrm{LixC} 6
$$

The negative electrode reaction during discharge is as follows:

$$
\mathrm{LixC} 6 \rightarrow \mathrm{xLi}+\mathrm{xe}+6 \mathrm{C}
$$

Lithium battery capacity calculation:

Lithium battery capacity $=$ load power $*$ daily working time * (storage days 1)/ discharge depth* system voltage.

A lithium battery can be used in combination with the solar cell panel and the controller. The real object diagram is shown in Figure 3, and the specific parameters are as follows.

The nominal voltage is $3.7 \mathrm{~V}$; the rated capacity is $200 \mathrm{mAh}$; the size is $42 * 30 * 7.8 \mathrm{~mm}$.

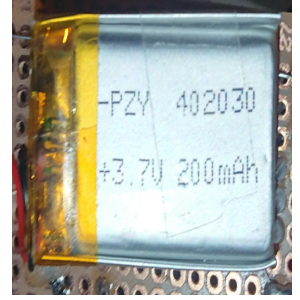

Fig. 3. physical diagram of lithium battery

When the lithium battery is connected with the controller, the voltage is to meet the requirements, and if the voltage of the lithium battery does not meet the requirement, several lithium batteries can be connected in series so as to achieve the purpose of use.

\subsection{Selection of DC-DC booster module.}

DC-DC-Its function is to control the rise and fall of DC voltage, and finally to convert the voltage into the DCDC converter of the required voltage value of the system, which can be divided into three types: step-up type, stepdown type and lift-down type. In general, the converter is comprised of an energy storage element and a power semiconductor device, wherein the energy storage element comprises an inductor, a capacitor, and the power semiconductor element comprises a diode, a switching tube. The on-off of the switching tube is controlled by using a pulse width modulation (PWM) technology to realize the direct-current voltage of a fixed value to be converted into a direct-current voltage of a required value.

The function of DC-DC is to control the rise and fall of DC voltage, and finally to convert the voltage into the voltage value of the system. The DC-DC conversion circuit includes voltage reduction conversion circuit (Buck circuit), boost conversion circuit (Boost circuit) and up and down voltage conversion circuit (Boost-Buck circuit). Because the output voltage of lithium battery is $3.7 \mathrm{~V}$, and the voltage of device is $5 \mathrm{~V}$, it is necessary to boost the voltage, that is, Boost circuit is selected as the boost circuit of this design, which makes the voltage become the $5 \mathrm{~V}$ voltage needed by the system. The boost chopper circuit diagram is shown in figure 4. the working waveform of the boost chopper circuit is shown in figure 5

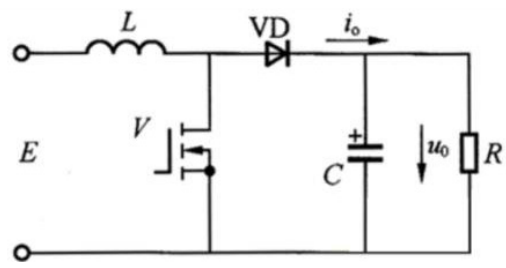

Fig. 4. boost chopper circuit diagram 


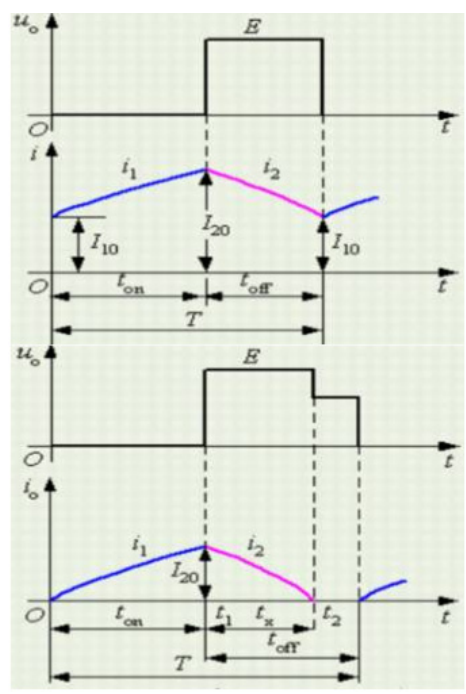

Fig. 5. working waveform diagram of boost chopper circuit

When the circuit is in a stable state, the energy accumulated by inductor $\mathrm{L}$ in a period $\mathrm{T}$ is equal to the energy released, that is,

$$
E I_{i} t_{o n}=\left(U_{0}-E\right) I_{i} t_{\text {off }}
$$

Simplification of gains

$$
U_{0}=\frac{t_{\text {on }}+t_{\text {off }}}{t_{\text {off }}} E=\frac{T}{t_{\text {off }}} E
$$

In the formula above:T/toff $\geq 1$, the output voltage is higher than the power supply voltage, and the amplifier calls the circuit a boost new wave circuit.

In (formula $13 \mathrm{~T} /$ toff $\geq 1$ indicates the step-up ratio. The size of the output voltage U0 can be changed by adjusting its size. Record the countdown of the boost ratio as $\beta$, that is $\beta=\frac{t_{\text {off }}}{T}$, the relationship $\beta$ with the conduction duty cycle $\rho$ is as follows

$$
\rho+\beta=1
$$

Therefore, (formula 14) can be expressed as

$$
U_{0}=\frac{1}{\beta} E=\frac{1}{1-\rho} E
$$

The voltage-boosting chopper circuit makes the output voltage higher than the power supply voltage. The key is two reasons: firstly, after the L energy storage, it has the effect of raising the voltage, and the other is that the capacitor $\mathrm{C}$ can hold the output voltage. In the above analysis, it is considered that the output voltage U0 does not change due to the action of the capacitor $\mathrm{C}$ during the pass-through state, but the $\mathrm{C}$-value is not likely to be infinite, and in this stage it will be discharged to the load, and the U0 will inevitably drop, so that the actual output voltage will be slightly lower than the result obtained by (15), However, when the capacitance $C$ value is large enough, the error is small and can be largely ignored.

If the loss in the circuit is ignored, the energy provided by the power supply is consumed by the load $\mathrm{R}$ only, that is,

$$
E I_{i}=U_{0} I_{0}
$$

shows that the boost chopper circuit can also be regarded as a DC transformer. According to the circuit structure and combination (17), the average $I_{0}$ of the output current is obtained.

$$
I_{0}=\frac{U_{0}}{R}=\frac{E}{\beta R}
$$

The supply current $\mathrm{I}_{\mathrm{i}}$ is obtained by (18).

$$
I_{i}=\frac{U_{0}}{E} I_{0}=\frac{E}{\beta^{2} R}
$$

A DC-DC boost module which can be used in conjunction with the selected lithium battery is considered. In fact, the figure is shown in figure 6. It can convert the input $3.7 \mathrm{~V}$ voltage to $5 \mathrm{~V}$.

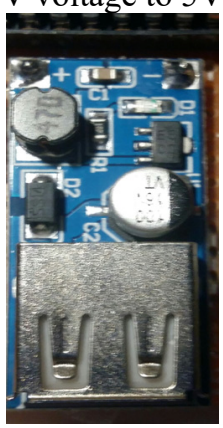

Fig. 6. Real object diagram of DC-DC boost module

The solar power supply system includes solar panels, solar control modules, lithium batteries and DC-DC boost modules, in which solar panels are the core part of the system, which can convert solar energy into electric energy, and then provide electric energy to the device for use, and can also store the excess electricity in the lithium battery for the next use, ensuring the ability of the device to use for a long time.The solar power supply system includes solar panels, solar control modules, lithium batteries and DC-DC solar control modules, which are used to control the charging of lithium batteries by solar panels and to control the power output to the load. Lithium battery is used to store the electric energy generated by solar panels and provide power for the device when needed. The function of DC-DC boost module in this design is mainly to convert the voltage of lithium battery into the voltage needed by the device. The schematic diagram of the solar power supply system is shown in figure 3-2

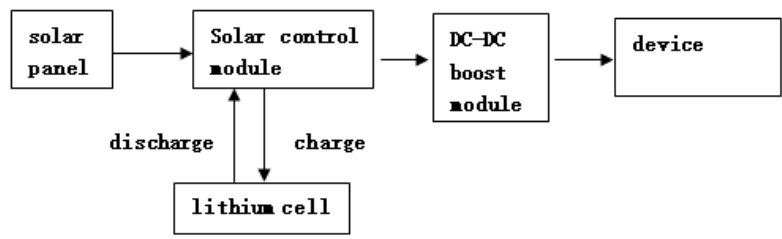

Figure.7.Schematic Diagram of the Solar Power Supply System 


\section{Conclusion}

According to the reasonable design, calculation and analysis of the design scheme, the selection of hardware circuit is determined, which provides sufficient conditions for the reasonable design of micro-solar power generation system.On this basis, the authors verify the stability and reliability of the system through experiments, which can provide stable dc voltage for the load equipment. The charging phenomenon of the system circuit is shown in the figure 8 .

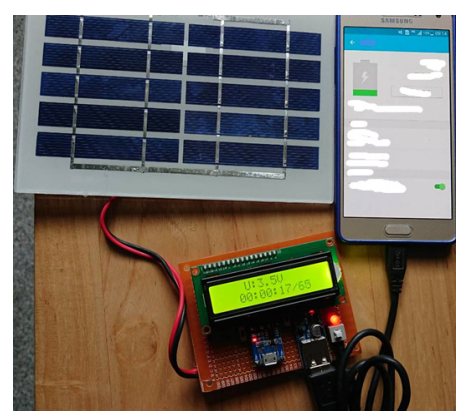

Figure.8.Schematic Diagram of the Solar Power Supply System

\section{Acknowledgement}

This paper is supported by NanTong Institute of Technology fund (Grant No. ZQNGG306).

\section{References}

1. Q.Wang, Y.Qin, T.Y.Li, E3S Web of Conferences. ICAEER2018 53, 1026(2018)

2. X.1.Liu.Wind Power.Solar Energy.1082(2009)

3. K.A.D , MPPT Method for PV System.Electric Power Systems Research.975(2009)

4. N.Johnstone, I.Haščič,D.Popp. Environmental and Resource Economics. 68(2017)

5. A. Maleki, A. Askarzadeh , Sustainable Energy Technologies and Assessments.147(2014) 